Journal of the Electrochemical Society, Vol. 149, No. 11, 2002, pp. B510-B519.

ISSN: 0013-4651

DOI: $10.1149 / 1.1513984$

http://www.electrochem.org/

http://scitation.aip.org/getpdf/servlet/GetPDFServlet?filetype=pdf\&id=JESOAN00014900001100B510000001\&idty pe $=$ cvips\&prog $=$ normal

(C) The Electrochemical Society, Inc. 2002. All rights reserved. Except as provided under U.S. copyright law, this work may not be reproduced, resold, distributed, or modified without the express permission of The Electrochemical Society (ECS). The archival version of this work was published in Journal of the Electrochemical Society, Vol. 149, No. 11, 2002, pp. B510-B519.

\title{
Localized Corrosion Growth Kinetics in AA2024 Alloys
}

\author{
Weilong Zhang and G. S. Frankel*
}

Fontana Corrosion Center, Department of Materials Science and Engineering, The Ohio State University, Columbus, Ohio

* Electrochemical Society Active Member.

The kinetics of localized corrosion in AA2024 alloys were studied using the foil penetration technique. The growth kinetics for localized corrosion in AA2024-T3 exhibited a strong anisotropy, being slower in the short transverse or plate through-thickness direction than in either the longitudinal or long transverse directions. This growth rate anisotropy depended on the grain size and aspect ratio, and was different for different forms of AA2024T3. The attack was primarily intergranular corrosion (IGC) at potentials of $-610 \mathrm{mV} \mathrm{SCE}$ and higher in $1 \mathrm{M} \mathrm{NaCl}$. The IGC growth rate was almost independent of potential over the range from -610 to $+500 \mathrm{mV}$ SCE, which suggests that only a small amount of the anodic dissolution current at the active IGC tip escapes from the IGC crevice. At lower potentials the attack was pit-like, and the rate of growth decreased with decreasing potential. Artificial aging of AA2024 to the T8 temper changed the attack from sharp IGC to selective grain dissolution, but the growth kinetics at high potentials were not strongly affected. The addition of nitrate increased the breakdown potential, and therefore decreased the growth kinetics in that region. At high potential, the nitrate had no effect. Sulfate addition had no significant effect at any potential studied.

The knowledge of localized corrosion growth kinetics is important from a practical point of view. Most high strength Al alloys widely used in aircraft structures are extremely susceptible to localized corrosion. While the total weight loss might be very small, local rates of attack can be very large and can lead to early catastrophic failure. A fundamental understanding of localized corrosion kinetics, including the effects of microstructure, potential, and solution environment on the development of localized corrosion, therefore, is critical for the development of predictive models.

Electrochemical techniques are commonly used for the study of localized corrosion growth. ${ }^{1}$ Localized corrosion kinetics, such as pit growth kinetics, are often described by a relationship between current density and applied potential. However, there are several problems associated with the use of electrochemical techniques. First, the active area during localized corrosion is typically unknown and difficult to measure. Many assumptions regarding the number and morphology of localized corrosion sites are needed in order to translate measured current transients into localized corrosion growth rate. This is complicated by the fact that localized corrosion may take more than one form, such as pits, crevices, and intergranular (IG) attack. Also, in the case of Al alloys, hydrogen evolution within the pits or intergranular attack regions can consume a reasonable fraction of the anodic current, which makes the measured net current unrepresentative of the metal anodic dissolution kinetics due to the availability of local cathodic reactions. Finally, localized corrosion in a real structure occurs under open circuit (OC) 
conditions. Under OC conditions, it is impossible to use electrochemical techniques for the quantitative study of localized corrosion kinetics. The study of single pits, formed by various approaches such as implantation, ${ }^{2}$ laser irradiation, ${ }^{3}$ or the use of an artificial pit electrode, ${ }^{4}$ provides an alternative way to address the localized corrosion kinetics, but there is no assurance that the behavior of these configurations is the same as that of real pits. Nonelectrochemical methods overcome many of these problems, and are useful for the study of localized corrosion growth kinetics.

The foil penetration technique is a nonelectrochemical approach that was developed in the early 1980 s for the study of pit growth rate. This technique offers advantages over electrochemical techniques because it measures the penetration time for the fastest-growing localized corrosion site for the determination of growth kinetics instead of using current density. The foil penetration has been used recently to study localized corrosion behavior in AA2024-T3. ${ }^{6,7}$ It was found that localized corrosion can take circuitous paths while penetrating through a wrought Al alloy foil. Microfocal X-ray radiography indicated that the attack morphology was much more convoluted than a hemispherical pit. ${ }^{6}$ The convoluted growth morphology of localized corrosion underscores the usefulness of the foil penetration technique for the measurement of growth kinetics. It was subsequently found that the growth kinetics of localized corrosion in AA2024-T3 exhibited a strong anisotropy at a controlled anodic potential; growth in the short transverse direction (through-thickness direction of a rolled plate) was found to be much slower than that in either the longitudinal or long transverse direction. ${ }^{7}$ This is in contrast to the pitting potentials, which were almost identical for the different orientations. ${ }^{8}$ The anisotropy occurred because pits that initiated on the surface often developed into intergranular corrosion (IGC) as they grew into the microstructure.

Pits and crevices have been shown to develop into other forms of localized corrosion, such as exfoliation or IGC. ${ }^{9-11}$ Since the growth kinetics of IGC or exfoliation corrosion can be very different from pit growth kinetics, it is important to study them independently. However, only a few reports of quantitative measurements of the kinetics of IGC in Al alloys exist, ${ }^{12,13}$ and little is known about the influence of alloy microstructure on localized corrosion kinetics.

In this work, localized corrosion kinetics in various tempers of AA2024 are quantitatively measured under OC and potentiostatic conditions using the foil penetration technique, with an aim to understand the effects of microstructure, orientation, artificial aging, potential, and solution environments. The results can be used to enhance predictive models for localized corrosion in aging aircraft.

\section{Experimental}

Materials and samples.-Three forms of commercial AA2024-T3 alloys were used for the foil penetration experiments: two plates with 1.9 and $8.9 \mathrm{~cm}$ thicknesses, respectively, and 0.2 $\mathrm{mm}$ thick sheet material. Unless stated otherwise, the results were obtained from the $1.9 \mathrm{~cm}$ thick plate. Samples with three different orientations, i.e. longitudinal (L), long transverse (LT), and short transverse (ST), were prepared using a band saw or electrical discharge machining (EDM). The convention utilized for the three different sections is given in Fig. 1, along with the microstructure of the $1.9 \mathrm{~cm}$ thick plate in the as-received T3 temper. The ST direction is the through-thickness direction in the rolled plate, and the L direction is along the rolling direction. The sections are labeled according to the perpendicular direction. Other tempers were obtained by artificially aging the as-received AA2024-T3 to $190^{\circ} \mathrm{C}$ for different times. ${ }^{14}$ Table I lists the 
materials and heat treatments used in this work. All samples were polished mechanically on both sides in ethanol with silicon carbide papers up to 800 grit. Such nonaqueous polishing minimized

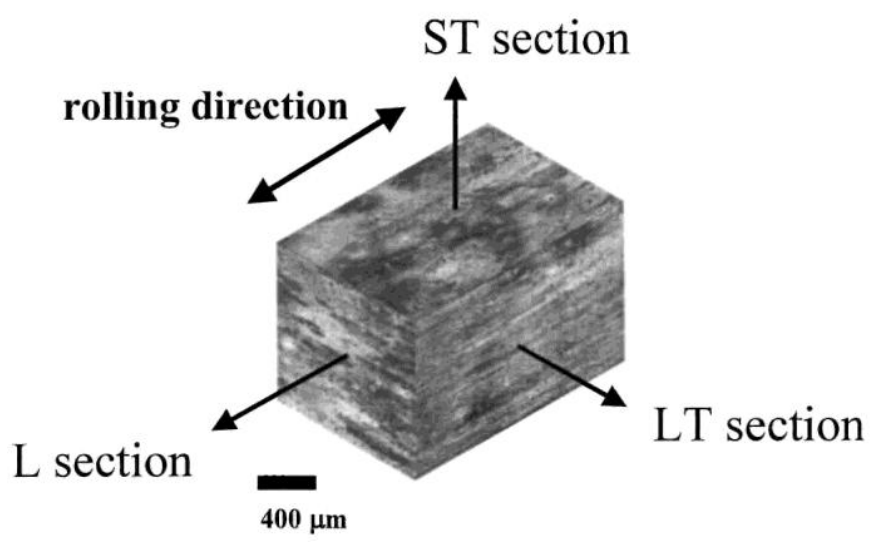

Figure 1. Metallographic sections of $1.9 \mathrm{~cm}$ AA2024-T3. Also given is the terminology used for the samples cut with different orientations.

corrosion during sample preparation. The samples were degreased with ethanol and then attached to the bottom of an acrylic cell by pressing against a Teflon knife-edge O-ring to expose an area of $1 \mathrm{~cm}^{2}$ for the foil penetration experiments.

Foil penetration experiments.-The principle and setup for foil penetration experiments have been described previously. In brief, this technique makes use of foil samples with varying thickness to measure the penetration time by detecting the resistance change in a piece of filter paper sandwiched between the back of the foil sample and a $\mathrm{Cu}$ foil. Most of the penetration experiments were conducted in oxygen-bubbled $1.0 \mathrm{M} \mathrm{NaCl}$ solution, either at $\mathrm{OC}$ or under anodic potentiostatic conditions. For a few penetration experiments at open circuit, a small amount of persulfate was added to the chloride solutions to make the penetration measurement in a reasonable amount of time. The purpose of oxygen gas bubbling was to maintain a constant supply of cathodic reactant and to aid convection in the cell. Ar-deaerated 1.0 M NaCl solution was used for a few penetration experiments, which lowers the OC potential (OCP) and allows testing penetration at low anodic potentials. In order to examine the influence of nitrate or sulfate addition on localized corrosion kinetics, nitrate- or sulfate-containing $1.0 \mathrm{M} \mathrm{NaCl}$ stock solutions were prepared and added in a designed volume ratio into the $1.0 \mathrm{M} \mathrm{NaCl}$ solution after the penetration experiments were started for 2 to $4 \mathrm{~min}$ to eliminate their effects on the initiation of localized corrosion. For potentiostatically controlled penetration experiments, a saturated calomel electrode (SCE) reference electrode and a Pt mesh counter electrode were used.

Most of the parameters related to the penetration experiments were the same as have been described previously. ${ }^{6}$ For example, the setpoint voltage of the detection circuit was 6.2 V. Prior to the penetration experiment, all samples were anodically polarized to $-290 \mathrm{mV} \mathrm{SCE}$ (approximately $400 \mathrm{mV}$ above the pitting potential) for $1 \mathrm{~s}$ to initiate pits, followed by an immediate change to the desired applied potential or release of potential control to open circuit. A Gamry Instruments (Warminster, PA) PC3 potentiostat and multiplexer, along with Gamry 
framework and custom-made programs were used to control the potential and acquire data.

Table II. Open circuit foil penetration results for AA2024-T3 samples.

\begin{tabular}{|c|c|c|c|c|c|c|c|}
\hline AA2024-T3 & & $\begin{array}{c}\text { Samples/ } \\
\text { thickness } \\
(\mathrm{mm})\end{array}$ & $\begin{array}{c}1 \mathrm{M} \mathrm{NaCl} \\
\text { Time } \\
\text { (h) }\end{array}$ & $\begin{array}{l}\text { OCP } \\
(\mathrm{mV} \\
\text { SCE) }\end{array}$ & $\begin{array}{c}\text { Samples/ } \\
\text { thickness } \\
(\mathrm{mm})\end{array}$ & $\begin{array}{c}1 \mathrm{M} \mathrm{NaCl}+ \\
5 \times 10^{-2} \mathrm{M} \\
\mathrm{Na}_{2} \mathrm{~S}_{2} \mathrm{O}_{8} \\
\text { Time } \\
\text { (h) }\end{array}$ & $\begin{array}{l}\text { OCP } \\
\text { (mV } \\
\text { SCE) }\end{array}$ \\
\hline $\begin{array}{l}1.9 \mathrm{~cm} \\
\text { thick } \\
\text { plate }\end{array}$ & ST & $\begin{array}{l}0.12 \\
0.21\end{array}$ & $\begin{array}{c}54.9 \pm 25.4 \\
\text { unpenetrated } \\
>450\end{array}$ & $\begin{array}{l}-640 \\
-640\end{array}$ & $\begin{array}{l}0.14 \\
0.24\end{array}$ & $\begin{array}{c}5.6 \pm 0.6 \\
20.0 \pm 7.7\end{array}$ & $\begin{array}{l}-620 \\
-620\end{array}$ \\
\hline alloy & $\mathrm{L}$ & $\begin{array}{l}0.12 \\
0.22 \\
1.10\end{array}$ & $\begin{array}{c}1.4 \pm 0.5 \\
2.1 \pm 0.7 \\
\text { unpenetrated } \\
\quad>267\end{array}$ & $\begin{array}{l}-630 \\
-630 \\
-630\end{array}$ & 0.24 & $1.6 \pm 0.5$ & -620 \\
\hline $\begin{array}{l}0.2 \mathrm{~mm} \\
\text { sheet } \\
\text { alloy }\end{array}$ & ST & 0.21 & $\begin{array}{c}50.6 \pm 23.5 \\
\text { others }>168\end{array}$ & -615 & 0.21 & $4.7 \pm 1.3$ & -610 \\
\hline
\end{tabular}

Table I. AA2024 materials and heat treatments.

\begin{tabular}{|c|c|c|}
\hline Temper & Heat treatments & Notes \\
\hline $0.2 \mathrm{~mm}$ thick sheet (T3) & None & As-received \\
\hline $1.9 \mathrm{~cm}$ thick plate (T3) & None & As-received \\
\hline $8.9 \mathrm{~cm}$ thick plate (T3) & None & As-received \\
\hline $\mathrm{T} 3+$ & $2.5 \mathrm{~h}, 190^{\circ} \mathrm{C}$ & $\begin{array}{l}\text { Using } 1.9 \mathrm{~cm} \text { thick } \mathrm{T} 3 \\
\text { plate as starting material }\end{array}$ \\
\hline $\mathrm{T} 8$ & $12 \mathrm{~h}, 190^{\circ} \mathrm{C}$ & $\begin{array}{l}\text { Using } 1.9 \mathrm{~cm} \text { thick T3 } \\
\text { plate as starting material }\end{array}$ \\
\hline T8+ & $36 \mathrm{~h}, 190^{\circ} \mathrm{C}$ & $\begin{array}{l}\text { Using } 1.9 \mathrm{~cm} \text { thick } \mathrm{T} 3 \\
\text { plate as starting material }\end{array}$ \\
\hline SHT & $1 \mathrm{~h}, 490^{\circ} \mathrm{C}$ & $\begin{array}{l}\text { Using } 1.9 \mathrm{~cm} \text { thick T3 } \\
\text { plate as starting material }\end{array}$ \\
\hline
\end{tabular}

\section{Results and Discussion}

Localized corrosion growth at open circuit.-Table II summarizes the OC penetration experiment results. The data reported here are the average values of four to six different samples. In $1 \mathrm{M}$ chloride solution, it took $54.9 \pm 25.4 \mathrm{~h}$ to penetrate about $0.12 \mathrm{~mm}$ thick ST samples prepared from the $1.9 \mathrm{~cm}$ thick plate. None of the $0.21 \mathrm{~mm}$ thick ST samples penetrated even after $450 \mathrm{~h}$ of exposure in $1 \mathrm{M} \mathrm{NaCl}$ at OC. Some of them should have penetrated after about $220 \mathrm{~h}$ based on the data of $0.12 \mathrm{~mm}$ thick samples if the localized corrosion growth followed a $t^{1 / 2}$ parabolic growth law as reported in the literature. ${ }^{5,15,16}$ The results suggest that either the time exponent, $n$, is less than 0.5 at OC or the localized corrosion was totally stifled in the ST direction. In the literature, a cube root growth law was reported for Al at OC under some conditions. ${ }^{17,18}$ In addition, the growth rate in the ST direction was much faster in the as-received $0.2 \mathrm{~mm}$ thick sheet than in the $1.9 \mathrm{~cm}$ thick plate material. The average penetration time for 0.21 $\mathrm{mm}$ thick sheet samples was about the same as that of $0.12 \mathrm{~mm}$ ST samples taken from the 1.9 $\mathrm{cm}$ thick plate. This is a result of the difference in microstructure between the sheet and plate 
materials. The effect of microstructure on growth kinetics is discussed below. It should be pointed out that the OCP of the AA2024-3 plate was slightly lower than that for the sheet samples in $1 \mathrm{M} \mathrm{NaCl}$ solutions, but the difference in OCP cannot account for such a large difference in penetration rates.

When the unpenetrated samples were dissembled from the cell, no penetrated pits were visible on the back side as expected. However, many penetrated pits were found on the unexposed surface of these same unpenetrated samples after they were left in laboratory air for several weeks. Localized corrosion apparently continued as a result of the aggressive environment trapped within occluded regions of the samples, and did not dry out quickly on removal from the bulk solution. This phenomenon is relevant to the real structures that go through cyclic exposure conditions, but was not studied further in this work.

The localized corrosion morphologies of ST samples exposed at OC were examined by metallographic cross section. Figure 2 shows the typical localized corrosion morphologies observed at OC. Hemispherical shape pits (Fig. 2b), intergranular attack, and exfoliation (Fig. 2 $\mathrm{a}, \mathrm{c})$ were all observed. In the case of IG attack, only a few grain boundaries were attacked. If either pitting or IG corrosion occurs primarily in the longitudinal direction instead of through the thickness direction, it will take a very long time to penetrate the foil. This may be the reason that some ST samples were not penetrated even after very long times.

The OC penetration rate on L samples taken from the $1.9 \mathrm{~cm}$ thick plate was considerably faster than both thin sheet and plate ST samples, as shown in Table II. On average, it took only about 1 to $2 \mathrm{~h}$ to penetrate 0.1-0.2 mm thick L samples, which was about 40-50 times shorter than that for the same thickness ST oriented samples. However, the penetration rate decreased quickly with time. All six $1.1 \mathrm{~mm}$ thick L samples were not penetrated after $267 \mathrm{~h}$ of exposure, which suggests that pit growth rate also does not follow a $t^{1 / 2}$ parabolic growth law in the $\mathrm{L}$ direction at open circuit. 


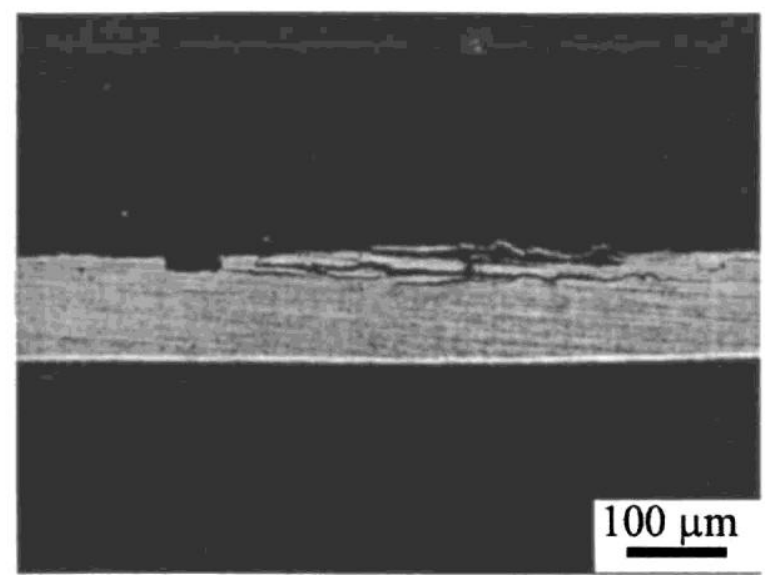

(a)

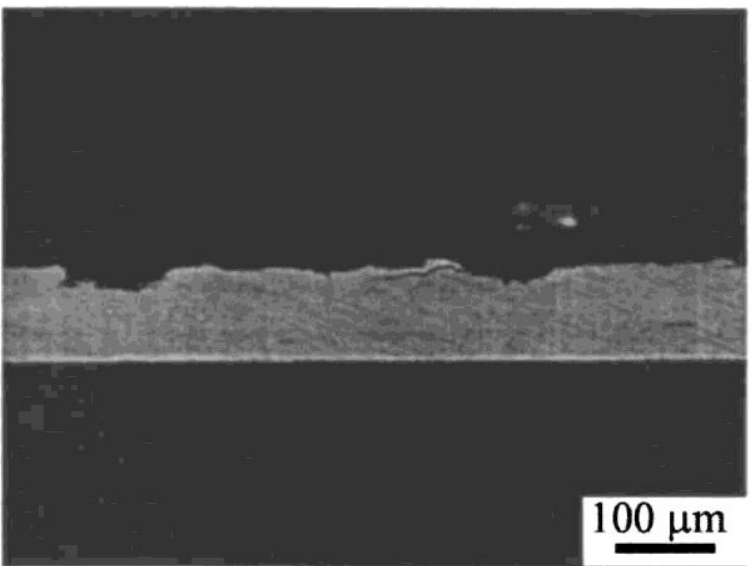

(b)

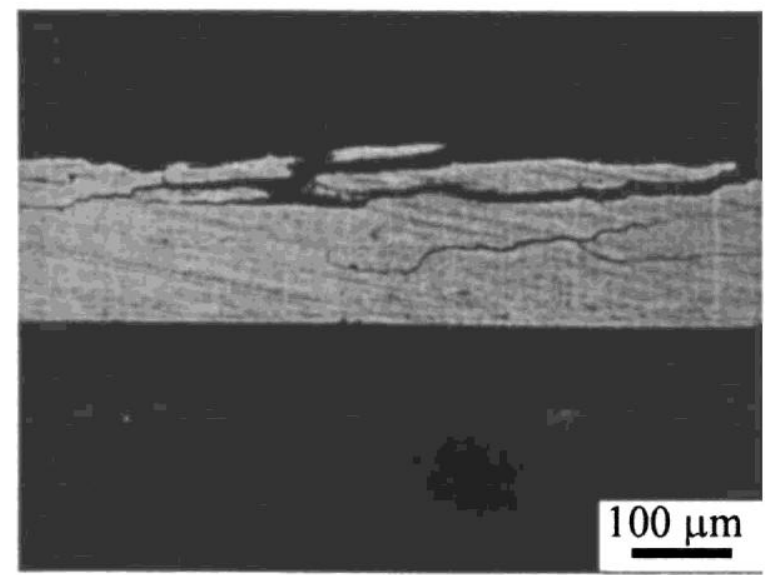

(c)

Figure 2. Metallographic cross sections showing localized corrosion morphologies for ST samples from $1.9 \mathrm{~cm}$ thick AA2024-T3 at the OCP ( $c a .-640 \mathrm{mV} \mathrm{SCE}$ ) in oxygenated $1 \mathrm{M} \mathrm{NaCl}$ after different times of exposure. (a) 89 h, (b) $332 \mathrm{~h}$, and (c) $450 \mathrm{~h}$. 


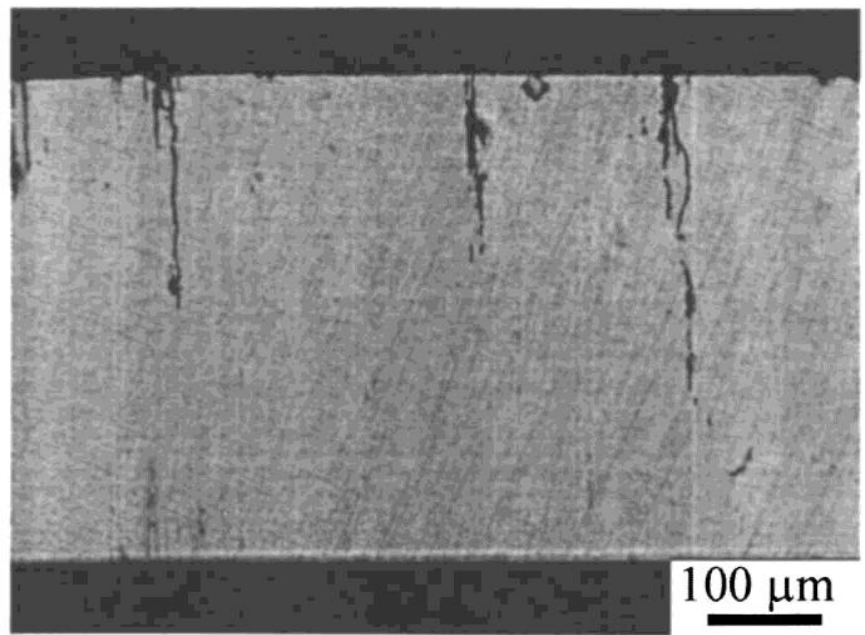

(a)

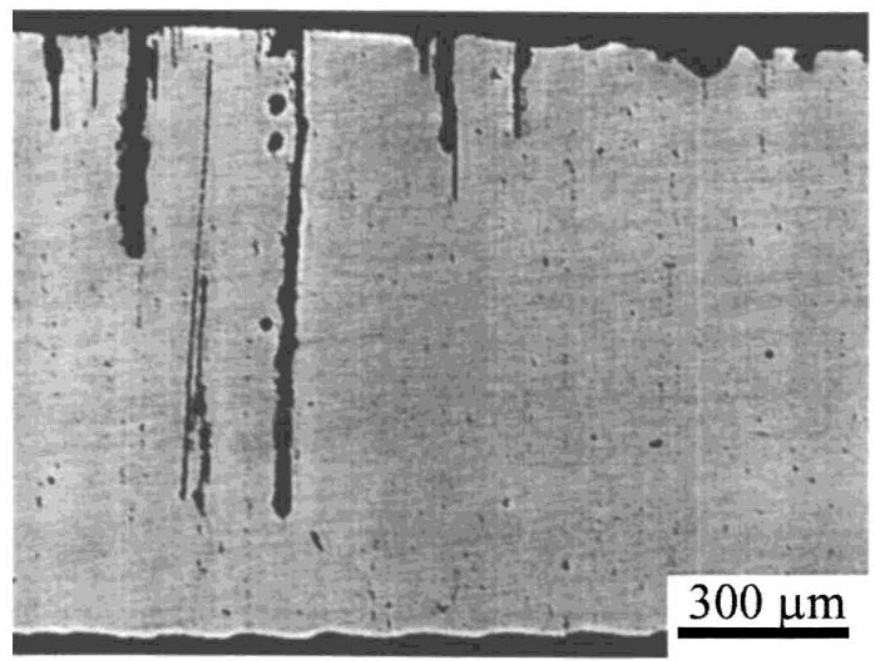

(b)

Figure 3. Metallographic cross sections showing localized corrosion morphologies for $\mathrm{L}$ samples from $1.9 \mathrm{~cm}$ thick AA2024-T3 at the OCP (ca. $-630 \mathrm{mV} \mathrm{SCE}$ ) in oxygenated $1 \mathrm{M} \mathrm{NaCl}$ after different times of exposure. (a) $10.3 \mathrm{~h}$ (b) $267 \mathrm{~h}$.

Figure 3 shows localized corrosion morphologies in L samples exposed at OC for different times. The attack is neither hemispherical pitting nor sharp IG corrosion. It may be considered to be either directional pitting or intergranular corrosion that has spread into the grain. Only a few grain boundaries were attacked on the cross section. 


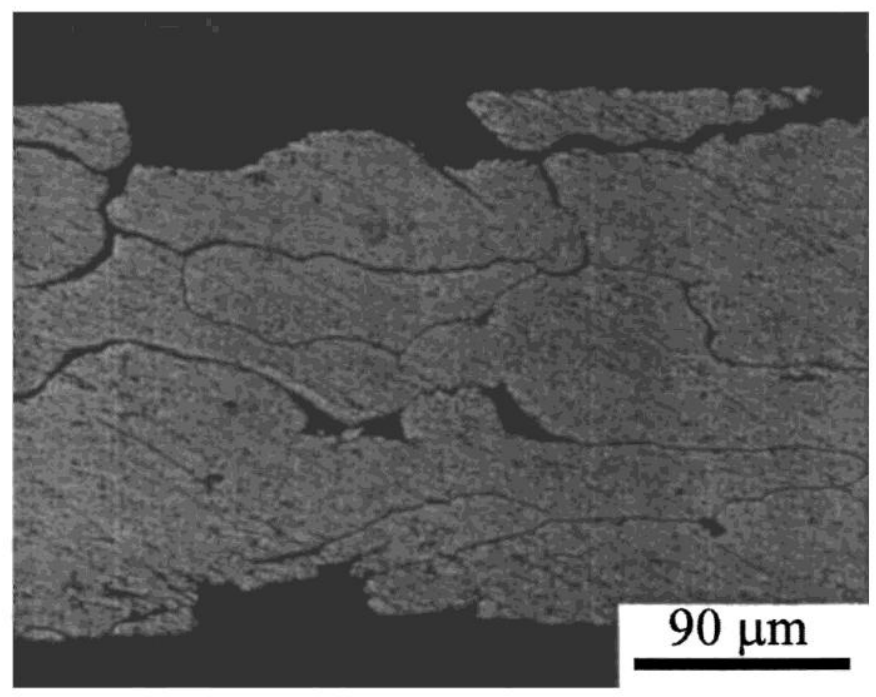

Figure 4. As polished metallographic cross section of ST sample of $1.9 \mathrm{~cm}$ AA2024-T3, which penetrated in $11.1 \mathrm{~h}$ in oxygen-bubbled $1 \mathrm{M} \mathrm{NaCl}+5 \times 10^{-2} \mathrm{M} \mathrm{Na}_{2} \mathrm{~S}_{2} \mathrm{O}_{8}$ at the OCP (ca. $\left.-610 \mathrm{mV} \mathrm{SCE}\right)$.

In order to accelerate localized corrosion kinetics at $\mathrm{OC}$, a small amount of oxidizing agent, persulfate, was added into chloride solution. The persulfate containing chloride solution was pumped in from a reservoir at $0.75 \mathrm{~mL} / \mathrm{h}$ to keep the oxidant concentration constant. As above, both L and ST samples were prepared from the $1.9 \mathrm{~cm}$ thick AA2024-T3 plate. The results are also summarized in Table II. The addition of a small amount of persulfate resulted a small increase in OCP, but dramatically increased the localized corrosion growth rate (reduced the penetration time) for ST samples. It took $20 \pm 7.7 \mathrm{~h}$ and $5.6 \pm 0.5 \mathrm{~h}$ to penetrate $0.24 \mathrm{~mm}$ and $0.14 \mathrm{~mm}$ thick ST samples, respectively, in oxygen bubbled $1 \mathrm{M} \mathrm{NaCl}+5 \times 10^{-2} \mathrm{MNa}_{2} \mathrm{~S}_{2} \mathrm{O}_{8}$ solutions at OC, which is about 10-20 times shorter than in the pure chloride solution. As with the pure chloride solution, the penetration rate was much faster in the as-received $0.2 \mathrm{~mm}$ sheet alloy than in the $1.9 \mathrm{~cm}$ thick plate alloy. While the penetration rate in the L direction increased with the addition of persulfate, the increase was not as great as for ST samples.

Metallographic cross sectioning confirmed that the attack was intergranular in $1 \mathrm{MNaCl}$ $+5 \times 10^{-2} \mathrm{MNa}_{2} \mathrm{~S}_{2} \mathrm{O}_{8}$ at $\mathrm{OC}$ (Fig. 4). The addition of a small amount of persulfate increases the susceptibility of AA2024-T3 to IG attack along with the small increase in OCP and large increase in growth rate. It should be mentioned that the $\mathrm{pH}$ of this solution (2.6) was lower than that of the pure chloride solution (5.8).

The OC foil penetration experiments indicated that localized corrosion growth depends on sample orientation, alloy microstructure, and solution environment. Localized corrosion that grew in the short transverse direction (through-thickness direction of a rolled plate) was found to propagate very slowly and in some cases never penetrate the foil sample at OC. The addition of a small amount of $\mathrm{Na}_{2} \mathrm{~S}_{2} \mathrm{O}_{8}$ increased greatly localized corrosion growth rate. However, it can be argued that persulfate addition may change the localized corrosion growth mechanism of AA2024-T3 in chloride containing environment. Another way to accelerate localized corrosion is to apply anodic potential. Therefore, the effect of applied potential on localized corrosion was studied. 
Effect of potential.-Figure 5 shows penetration results for L sections of AA2024-T3 (from $1.9 \mathrm{~cm}$ thick plate) at anodic potentials ranging from -675 to $+500 \mathrm{mV}$ SCE. The penetration time was plotted in a logarithmic scale to highlight the differences. The penetration

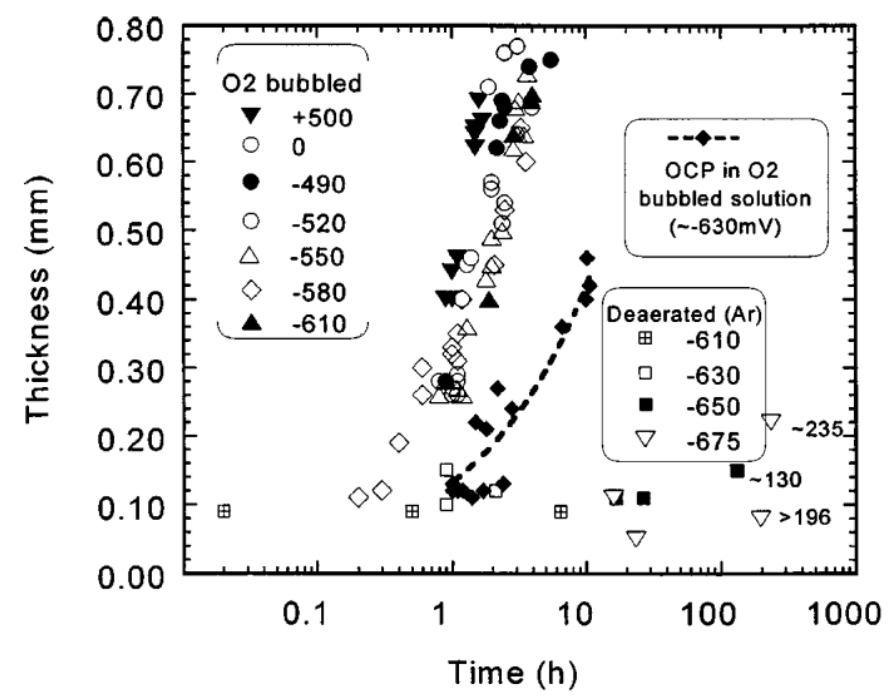

Figure 5. Penetration behavior for $\mathrm{L}$ samples of $1.9 \mathrm{~cm}$ thick AA2024-T3 in oxygen or Ar bubbled $1 \mathrm{M} \mathrm{NaCl}$ at potentials from $-675 \mathrm{mV}$ to $+500 \mathrm{mV} \mathrm{SCE}$.

rate was found to increase compared to that at $\mathrm{OC}$, but the rate was almost independent of potential over a wide range from -610 to $+500 \mathrm{mV} \mathrm{SCE}$. The attack is IG in nature in this potential range, so the measured data reflect the IGC propagation rate. A cross-sectional micrograph of the sharp IGC attack observed in this potential range was given in a previous publication. Similar IGC was observed throughout the potential range.

The potential-independent growth rate suggests that intergranular propagation might be under mass transport control since electrochemical kinetics are often reported to be potential independent at high anodic potentials as a result of transport limited dissolution. However, masstransport limited dissolution is typically associated with the formation of a salt film on the metal surface and electropolishing of the metal, which smooths the surface, leading to isotropic growth. However, the IGC growth morphology is roughened and not smoothed. The attack is limited to a narrow region near the grain boundaries so that the grains are immune to attack. The tortuous path from the active IGC tip to the bulk would present a transport barrier that promotes transportlimited dissolution. However, this phenomenon is only possible if there are critical conditions in the IGC crack that allow dissolution of the grain boundary regions, but prevent dissolution of the grains.

The observation of highly localized IG attack combined with only slight dependence of rate on applied potential can be explained if most of the anodic current generated by the local dissolution was consumed by cathodic reactions within the grain boundary (GB) crevice, so that little came out for collection by the potentiostat. The potential applied to the exposed surface by the potentiostat would only affect reactions for which the current exited to the bulk solution. The applied potential would have no effect on reactions that are essentially isolated from the bulk 
solution. It has been reported that about $15 \%$ of the anodic current generated in two-dimensional thin film pits is consumed by local cathodic reactions. ${ }^{1}$ A similar value was reported for $\mathrm{Al}$ artificial crevice electrodes. ${ }^{19}$ Recent work by Ramgopal et al. ${ }^{20}$ suggests that the fraction of cathodic reaction within a sharp IGC crevice can be much higher. The solute depleted zones (SDZ) near the grain boundaries are considered to be the site for local attack, but $\mathrm{Cu}$-rich $\mathrm{S}$ phase particles at the GB are also attacked. These particles have been shown to release $\mathrm{Cu}$. Deposition of $\mathrm{Cu}$ on the grain faces lining the GB crevice would protect those faces from attack, and provide a cathodic site that would consume current generated by IGC at the attack front. Since most of the current would not escape from the GB crevice, the dissolution rate of the front would not be strongly dependent on external applied potential. This explains the localized nature of the attack and the apparent potential independence.

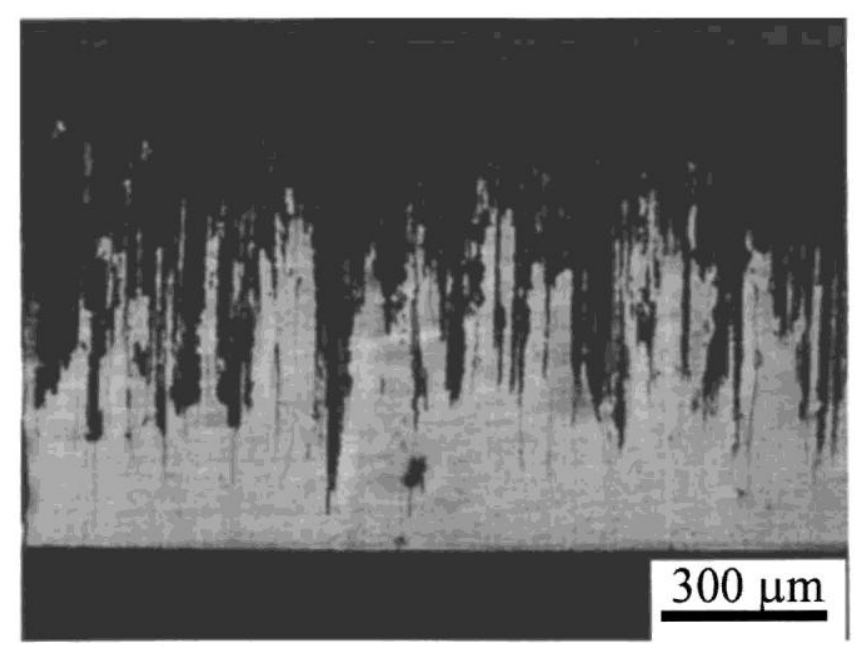

(a)

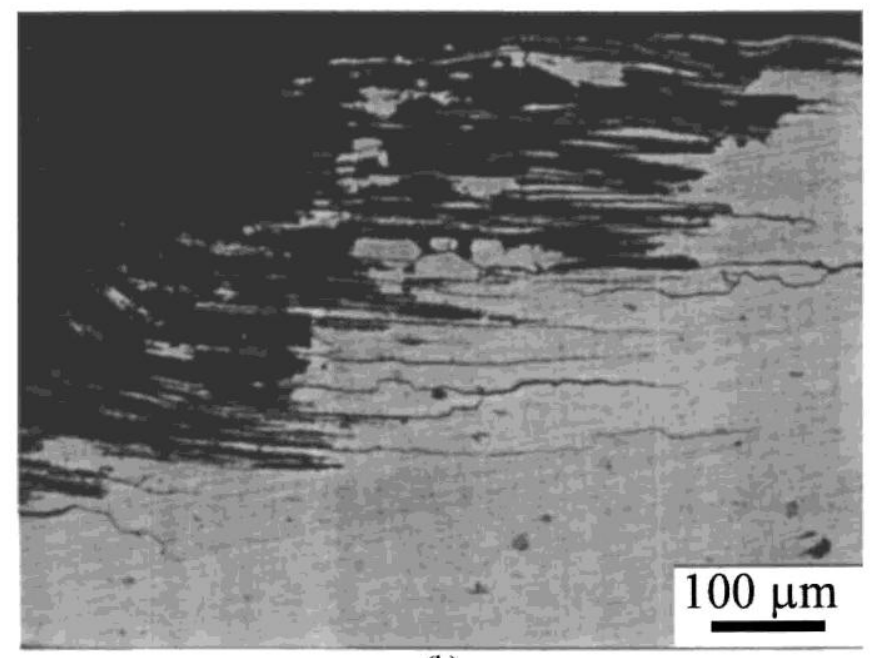

(b)

Figure 6. As polished metallographic cross sections of AA2024-T3 samples penetrated at $+500 \mathrm{mV}$ in oxygen bubbled $1 \mathrm{M} \mathrm{NaCl}$ solution (a) L sample after $3.4 \mathrm{~h}$ (b) ST sample after $3.3 \mathrm{~h}$. 
The attack morphology was slightly different at the highest potential studied, $+500 \mathrm{mV}$ SCE. Figure 6a shows that the attack on an L section was greatly isotropic, particularly near the exposed surface. At the bottom, where the attack penetrated the sample, sharp IG corrosion can be seen. However, the grain walls are not totally protected and the attack penetrated the grains at $+500 \mathrm{mV} \mathrm{SCE}$ as it deepened by IGC. The cross section of an ST sample penetrated at $+500 \mathrm{mV}$ SCE provides more evidence for this conclusion, Fig. 6b. This ST sample had a thickness of about $0.6 \mathrm{~mm}$, but was penetrated in oxygenated $1 \mathrm{M} \mathrm{NaCl}$ solution after only $3.2 \mathrm{~h}$ at $+500 \mathrm{mV}$, which is much faster than predicted by parabolic growth kinetics for ST samples, and similar to what would be predicted for an L section of this thickness. The attack front was advancing by IGC, but the grains were consumed behind the attack front.

At lower potentials, the penetration rates were dependent on potential, Fig. 5. The penetration rate decreased when the potential was decreased only $20 \mathrm{mV}$ from $-610 \mathrm{mV}$ SCE to the OCP in oxygen-bubbled 1.0 M NaCl, which was about $-630 \mathrm{mV} \mathrm{SCE}$ for AA2024-T3. The penetration rate was almost the same at $-630 \mathrm{mV}$ SCE in both oxygen aerated solution at OC and under potentiostatic control in argon deaerated solution. Deaerated solutions were used for ex- periments at low potential to avoid cathodic polarization, which would result in local $\mathrm{pH}$ changes associated with the net cathodic current at the surface. Although the scatter in the data was large at low potentials, the penetration rates seemed to decrease with decreasing potential below about $-610 \mathrm{mV}$ SCE, Fig. 5 .

The localized corrosion morphology also changed as the applied potential decreased. Figure 7 shows metallographic cross sections of L samples exposed at -610 to -675 $\mathrm{mV}$ SCE. As reported previously, at $-580 \mathrm{mV} \mathrm{SCE}$, the attack was sharp IGC. At $-610 \mathrm{mV}$, which is about $20 \mathrm{mV}$ higher than the OCP in the $\mathrm{O}_{2}$ bubbled $1 \mathrm{M} \mathrm{NaCl}$ solution, the attack was still sharp IGC (Fig. 7a), but the number of attacked boundaries per unit of cross-sectional area decreased. The localized corrosion morphology changed to pitlike attack for the samples exposed at -650 and $-675 \mathrm{mV} \mathrm{SCE}$, Fig. $7 \mathrm{~b}$ and c. 


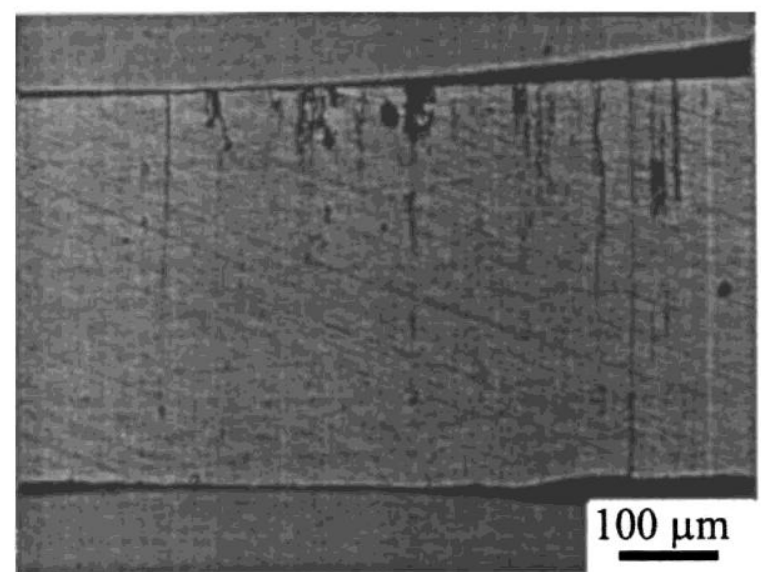

(a)

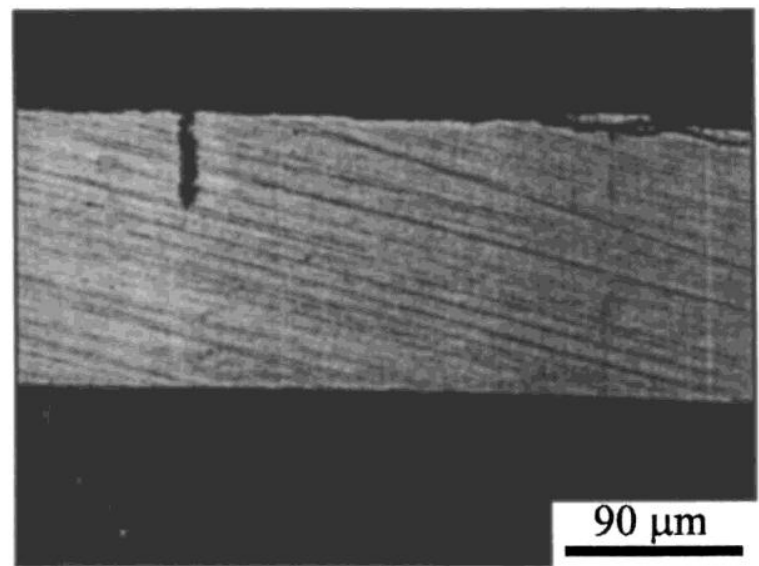

(b)

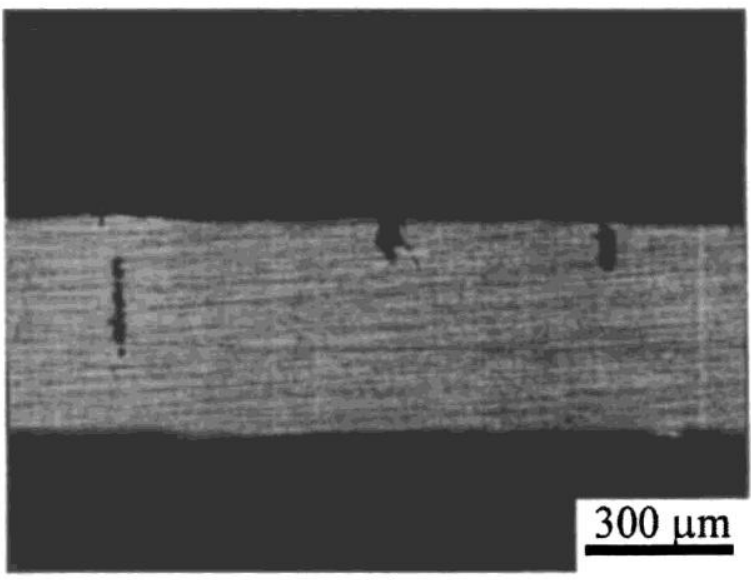

(c)

Figure 7. As polished metallographic cross sections of L samples of $1.9 \mathrm{~cm}$ thick AA2024-T3 penetrated in oxygenated $1 \mathrm{M} \mathrm{NaCl}$. (a) $5 \mathrm{~h}$ at $-610 \mathrm{mV} \mathrm{SCE}$, (b) $16.5 \mathrm{~h}$ at $-650 \mathrm{mV} \mathrm{SCE}$, and (c) $267 \mathrm{~h}$ at $-675 \mathrm{mV} \mathrm{SCE}$. 




Figure 8. Penetration behavior for ST samples from $1.9 \mathrm{~cm} \mathrm{AA2024-T3} \mathrm{at}-520$ to $-580 \mathrm{mV} \mathrm{SCE}$ in $1 \mathrm{M} \mathrm{NaCl}$.

Figure 8 shows penetration results for ST samples in the potential range from -580 to $-520 \mathrm{mV}$ SCE. The data look more scattered than those of $\mathrm{L}$ samples, but, in general, the penetration rate for ST samples is also almost independent of potential in the studied potential range. As discussed earlier, the penetration rate is very slow on ST samples at OC in oxygen bubbled $1 \mathrm{M} \mathrm{NaCl}$. Table III shows that the penetration rates are much slower at -645 and -660 $\mathrm{mV}$ SCE than at OC in the oxygenated solution ( $-640 \mathrm{mV} \mathrm{SCE})$. None of three ST samples with thickness about $0.1 \mathrm{~mm}$ penetrated after $260 \mathrm{~h}$ of exposure at $-660 \mathrm{mV} \mathrm{SCE}$. At $-645 \mathrm{mV} \mathrm{SCE}$, it took about $150 \mathrm{~h}$ to penetrate one $0.12 \mathrm{~mm}$ thick ST sample while other two ST samples did not penetrate after $260 \mathrm{~h}$ of exposure. Figure 9 shows the cross sections of those samples. No sharp IGC occurred under these conditions. The attack was pitlike.

Table III. Penetration experiment results for ST samples at low potentials in Ar-deaerated 1 M NaCl.

\begin{tabular}{lccc}
$\begin{array}{l}\text { ST sample } \\
\text { thickness } \\
(\mathrm{mm})\end{array}$ & $\begin{array}{c}\text { Applied potentials } \\
(\mathrm{mV} \text { SCE })\end{array}$ & $\begin{array}{c}\text { Penetration time } \\
(\mathrm{h})\end{array}$ & Notes \\
\hline 0.08 & -645 & $\begin{array}{c}\text { Unpenetrated, } \\
>260\end{array}$ & $\begin{array}{c}\text { Average } \\
\text { penetration } \\
\text { time is } \\
\text { about } 55 \pm 25 \\
\text { h at open circuit }\end{array}$ \\
0.12 & -645 & $\sim 150$ & $\begin{array}{c}(c a .-640 \mathrm{mV} \mathrm{SCE}) \\
0.14\end{array}$ \\
& -645 & $\begin{array}{c}\text { Unpenetrated } \\
>260\end{array}$ \\
0.09 & -660 & $\begin{array}{c}\text { Unpenetrated } \\
>260\end{array}$ \\
0.10 & -660 & $\begin{array}{r}\text { Unpenetrated } \\
>260\end{array}$ \\
0.12 & -660 & Unpenetrated & \\
& & &
\end{tabular}






(a)

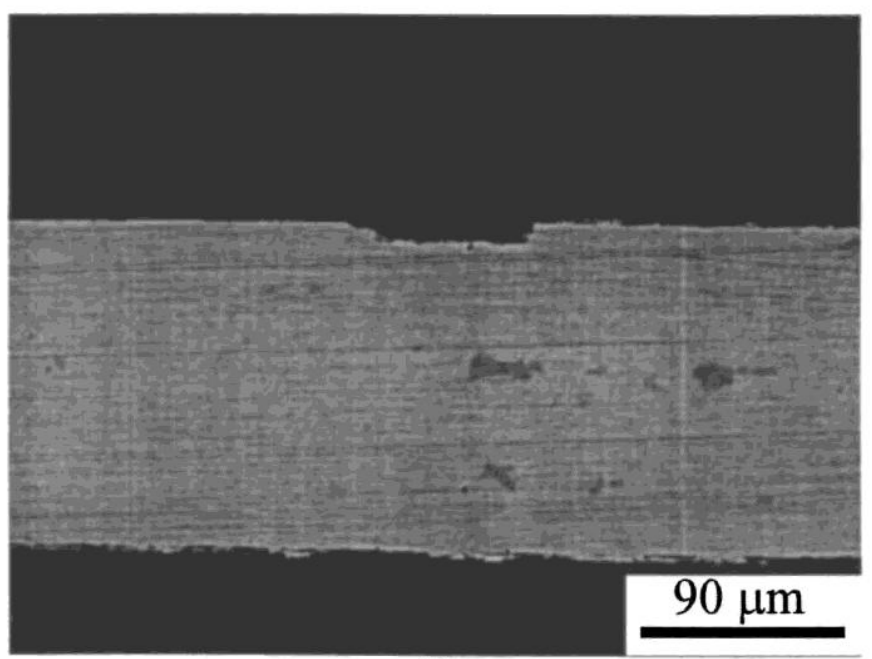

(b)

Figure 9. As polished metallographic cross sections of ST samples of $1.9 \mathrm{~cm}$ AA2024-T3 in Ar-deaerated $1 \mathrm{M}$ $\mathrm{NaCl}$, (a) $260 \mathrm{~h}$ at $-645 \mathrm{mV}$ SCE, (b) $260 \mathrm{~h}$ at $-660 \mathrm{mV}$ SCE.

Effect of microstructure.-As reported previously, ${ }^{7}$ the growth of localized corrosion in the $1.9 \mathrm{~cm}$ thick AA2024-T3 plate exhibited vast differences in the penetration rates at $-580 \mathrm{mV}$ $\mathrm{SCE}$, depending on the direction relative to the rolling direction. This anisotropy of localized corrosion growth was also observed in the $8.9 \mathrm{~cm}$ thick AA2024-T3 plate. Figure 10 shows foil penetration results for ST, L, and LT sections prepared from the $8.9 \mathrm{~cm}$ thick AA2024-T3 plate exposed to the oxygenated $1.0 \mathrm{M} \mathrm{NaCl}$ solution at the same potential of $-580 \mathrm{mV} \mathrm{SCE}$. The lines in the figure are fits of the data to the curve $d=a \times t^{1 / 2}$. The values of $a$, determined from the fits, are $0.123\left(R^{2}=0.92\right), 0.209\left(R^{2}=0.89\right)$, and $0.271\left(R^{2}=0.97\right)$, for the ST, LT, and L sections, respectively. The $8.9 \mathrm{~cm}$ thick AA2024-T3 plate also exhibits anisotropic growth of localized corrosion at $-580 \mathrm{mV} \mathrm{SCE}$, but the anisotropy is less than that found for the $1.9 \mathrm{~cm}$ thick plate. ${ }^{7}$ The microstructure is the only reason for the difference because both alloys have 
same nominal composition and are in the same temper. The results suggest that grain structure (both grain size and aspect ratio) may influence localized corrosion growth kinetics, mainly IGC growth under these conditions.

Figure 11 shows penetration results for ST samples prepared from three types of AA2024-T3 materials: $0.2 \mathrm{~mm}$ thick sheet, $1.9 \mathrm{~cm}$, and $8.9 \mathrm{~cm}$ thick plates. Since the microstructure in the mid-plane of a thick plate is reported to be different than that at the surface,

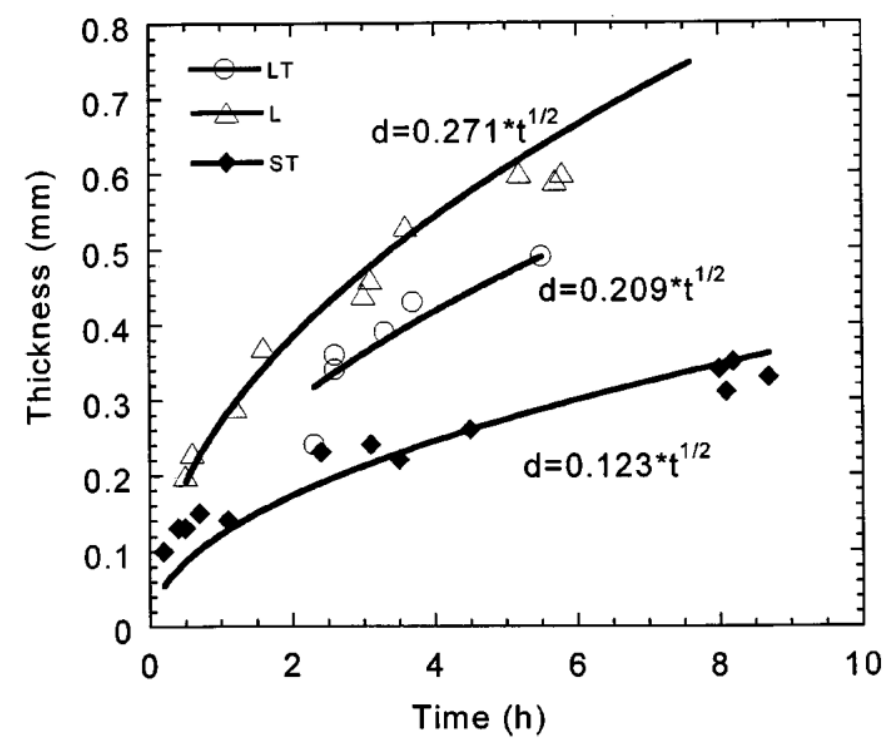

Figure 10. Penetration behavior for samples from $8.9 \mathrm{~cm}$ thick plate of AA2024-T3 in oxygenated $1 \mathrm{M} \mathrm{NaCl}$ at $-580 \mathrm{mV}$ SCE.

ST samples of the $1.9 \mathrm{~cm}$ thick plate were taken from both close to the surface of the alloy plate and from the midplane. ST samples from the $8.9 \mathrm{~cm}$ thick plate were prepared from a region close to the surface of the plate. The penetration rate in the ST samples from the $8.9 \mathrm{~cm}$ thick plate was found to be the fastest. Interestingly, the penetration rate in the $0.2 \mathrm{~mm}$ thick sheet is between that of the $9.8 \mathrm{~cm}$ thick and $1.9 \mathrm{~cm}$ thick plate. Midplane ST samples from the $1.9 \mathrm{~cm}$ plate show a much slower penetration rate than these from close to the surface of the plate. The differences in penetration rates are a result of differences in the grain structure (grain size and aspect ratio) among these alloys. Figures 12-14 show metallographic cross sections of these penetrated ST samples. Both the $0.2 \mathrm{~mm}$ thick sheet and the ST samples from the surface of the $8.9 \mathrm{~cm}$ thick plate have equiaxed grain structure with fine grains (Fig. 12 and 13), which is probably due to recrystallization during alloy metallurgical processing. In contrast, the ST samples from the $1.9 \mathrm{~cm}$ thick plate sample show a strongly elongated grain structure. Severe exfoliation occurred on the midsection ST as a result of more elongated grain structure in this plane (Fig. 14). This result further supports the notion that both grain size and aspect ratio affect localized corrosion kinetics and morphology. Qualitatively, it appears that the fine and equiaxed grain structure reduces the anisotropy of IGC growth, while elongated grain structure increases anisotropic IGC growth because of the difference in IG path length through the foils. A statistical model that relates IGC kinetics and microstructure, including grain size and aspect ratio, will be 
presented in another paper.

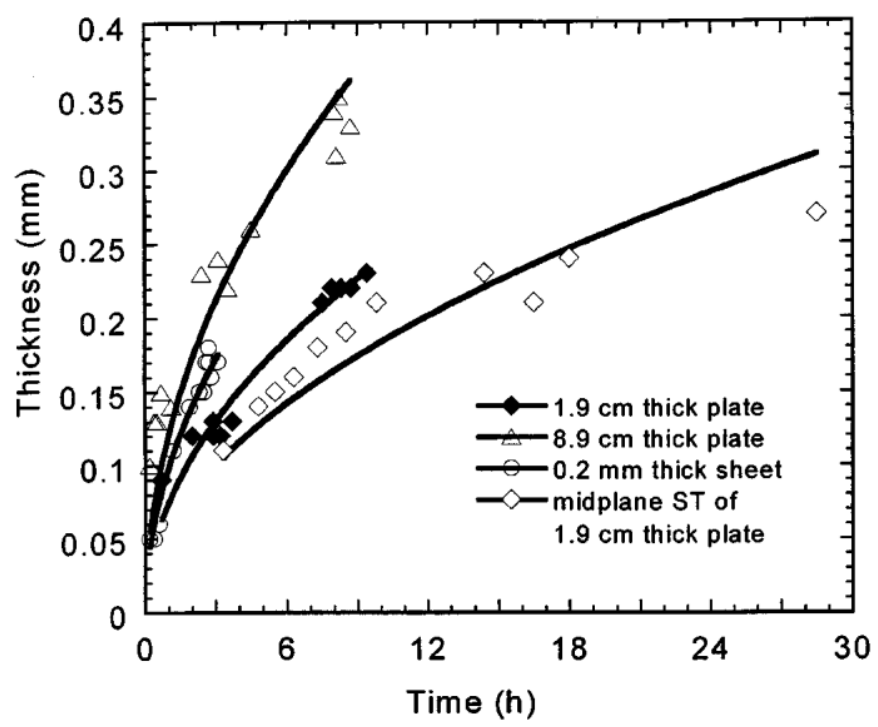

Figure 11. Penetration rates for ST samples from various forms of AA2024-T3 in oxygenated $1 \mathrm{M} \mathrm{NaCl}$ at $-580 \mathrm{mV}$ SCE.

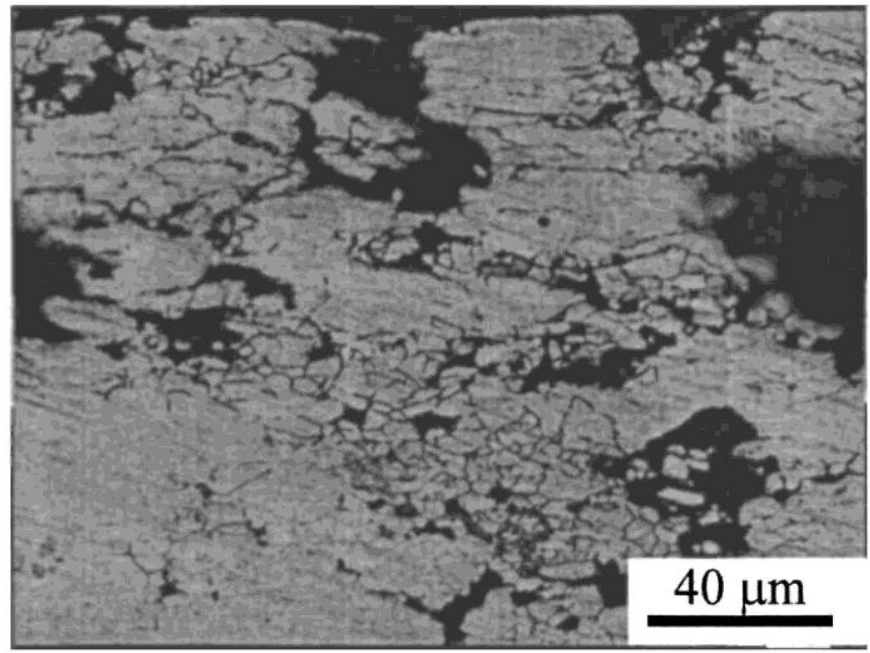

Figure 12. As polished metallographic cross section of ST sample from close to the surface of $8.9 \mathrm{~cm} \mathrm{AA2024-T3}$ plate penetrated at $-580 \mathrm{mV} \mathrm{SCE}$ in $1 \mathrm{M} \mathrm{NaCl}$, showing pitting, and IG attack. 


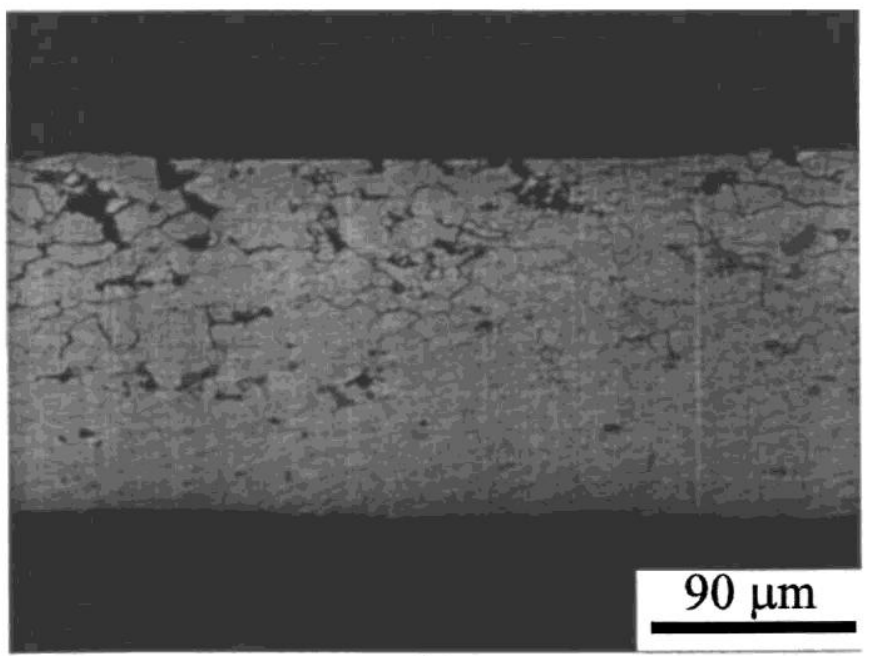

(a)

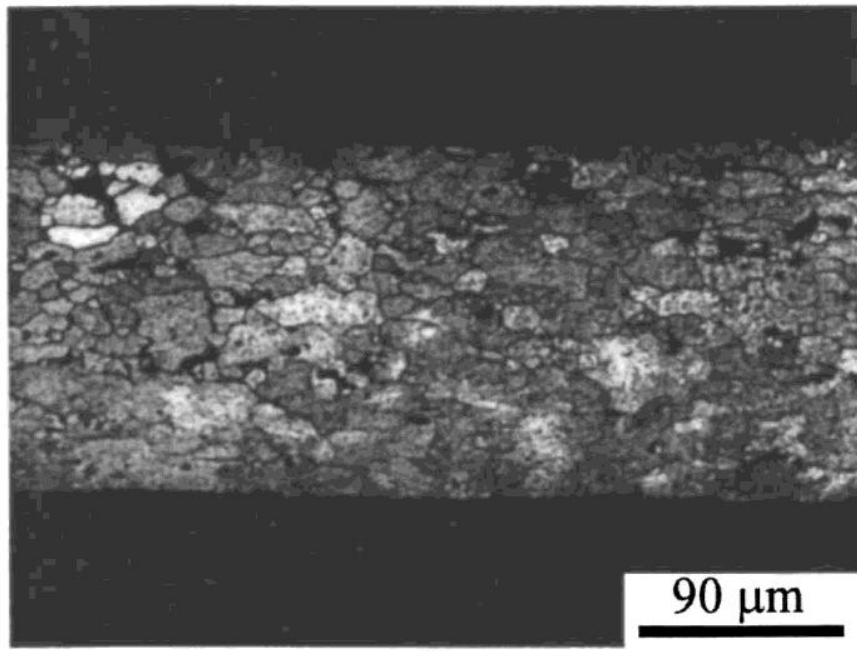

(b)

Figure 13. Metallographic cross sections of ST samples of $0.22 \mathrm{~mm}$ thick AA2024-T3 (ST) penetrated at $-580 \mathrm{mV}$ SCE in $1 \mathrm{M} \mathrm{NaCl}$ showing pitting and IG attack. (a) As-polished, (b) etched. 


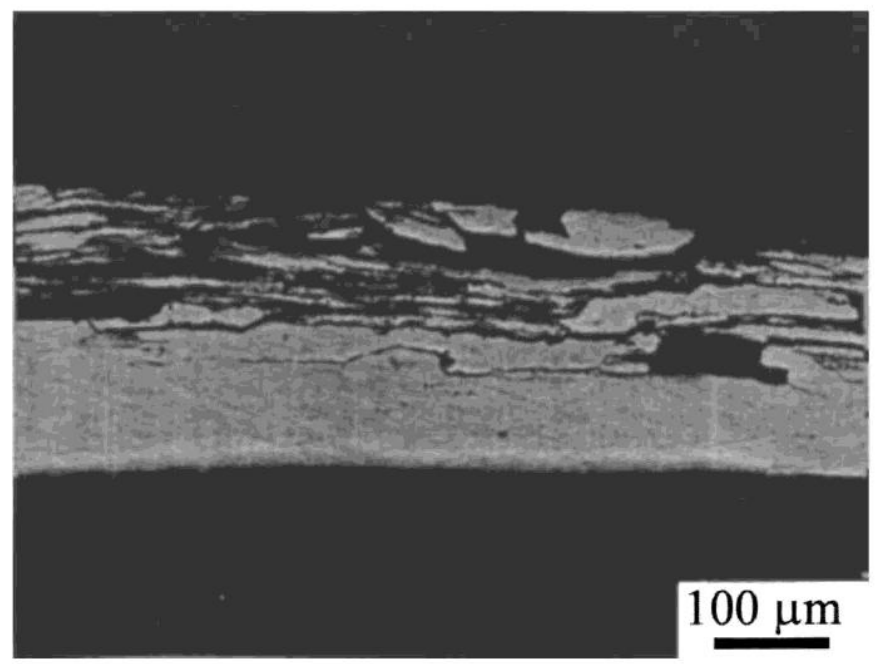

Figure 14. As polished metallographic cross section of ST samples from midsection of $1.9 \mathrm{~cm}$ AA2024-T3 penetrated at $-580 \mathrm{mV}$ SCE showing pitting, IG attack, and exfoliation.

Effect of artificial aging.-It is generally accepted that inter-granular corrosion in high strength $\mathrm{Al}-\mathrm{Cu}$ and $\mathrm{Al}-\mathrm{Cu}-\mathrm{Mg}$ alloys is associated with precipitates at grain boundaries. ${ }^{22,23}$ The idea of the existence of a preferential anodic path as a result of solute enrichment in grain boundary regions has been well known for a while. However, it is not clear what makes the grain boundary so susceptible in AA2024-T3 under these conditions, i.e., whether it is the precipitation of intermetallic particles in the grain boundary, the copper-depleted zone along the grain boundary, a combination of the two, or the grain boundary structure. To address this issue, AA2024-T3 was artificially aged at $190^{\circ} \mathrm{C}$ for various times before testing by foil penetration experiment.

Figure 15 shows penetration results at $\mathrm{OC}$ and at various applied potentials for $\mathrm{L}$ sections of AA2024-T8 in oxygenated $1.0 \mathrm{M} \mathrm{NaCl}$. The OCP for T8 samples in this solution was considerably lower than for $\mathrm{T} 3$ samples, consistent with a decrease in breakdown potential in a deaerated solution. As in the case of the T3 temper, the penetration rate was found to be much slower at the OCP than that at high anodic potentials. Also like T3, the penetration rate was not much affected by the value of applied potential in the range from -610 to $-490 \mathrm{mV}$ SCE. However, as reported previously, the attack morphology is selected grain dissolution, not sharp IG attack as observed in the case of the T3 sample. Figure 16 shows metallographic cross sections of a T8 sample penetrated at OC (about $-730 \mathrm{mV} \mathrm{SCE}$ ) and at $-580 \mathrm{mV} \mathrm{SCE}$. The number of grains attacked increased with increasing anodic potential. 


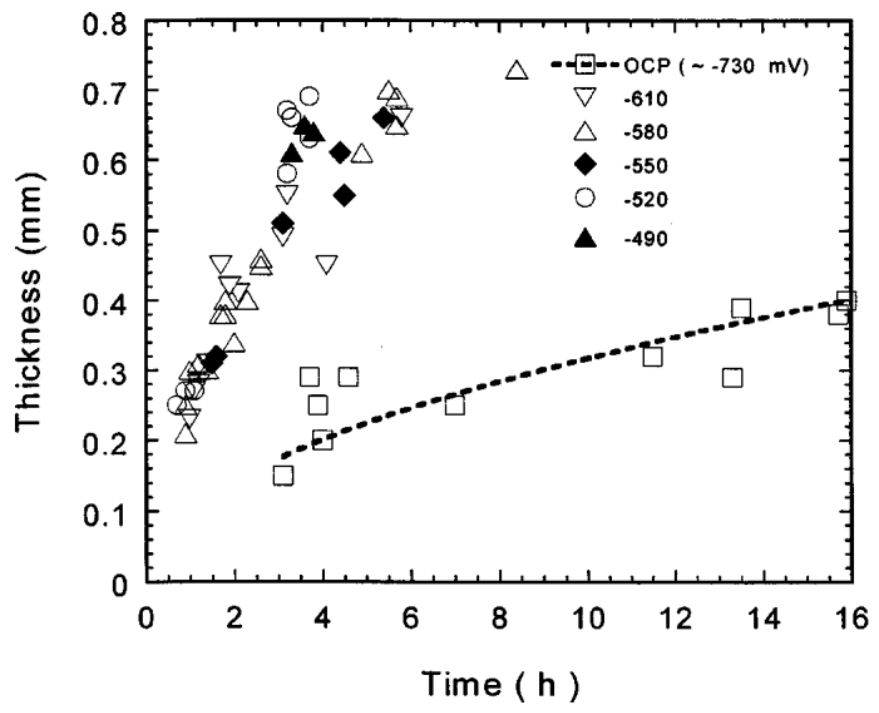

Figure 15. Penetration behavior of $\mathrm{L}$ samples of AA2024-T8 at different potentials in $\mathrm{O}_{2}$ bubbled $1 \mathrm{M} \mathrm{NaCl}$. 


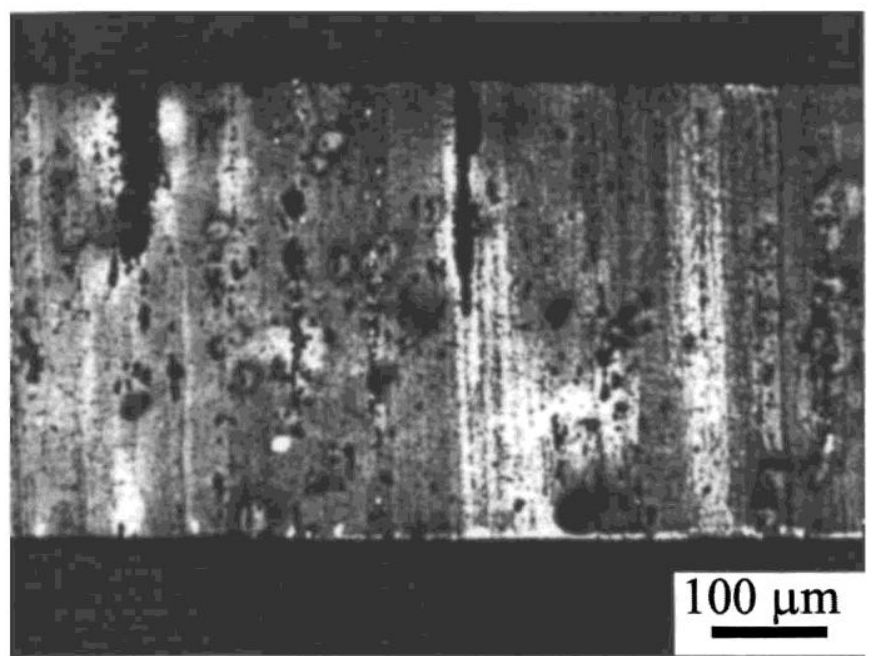

(a)

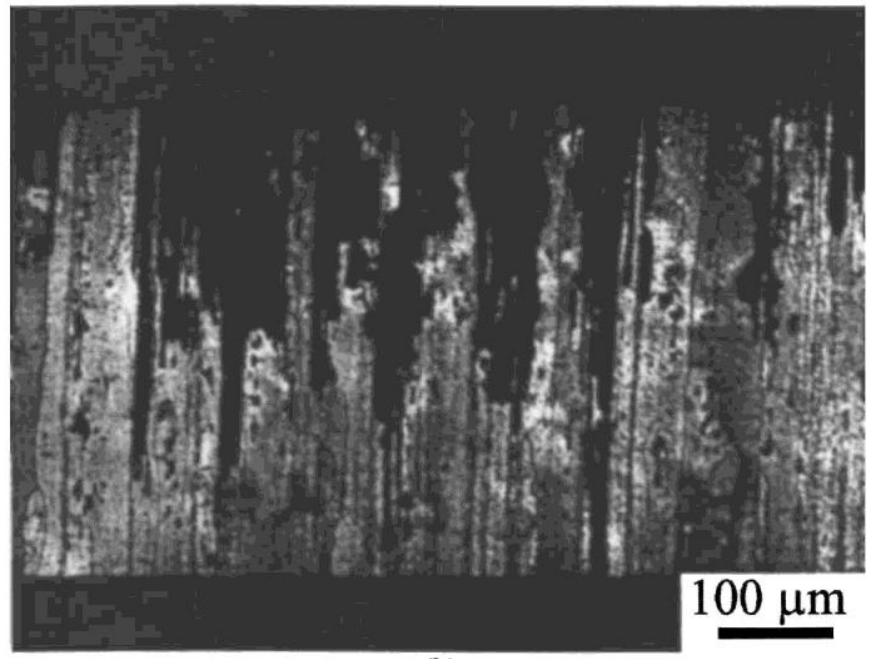

(b)

Figure 16. Etched metallographic cross sections of L samples of AA2024-T8 penetrated at (a) OCP (ca. $-740 \mathrm{mV}$ SCE), (b) at $-580 \mathrm{mV} \mathrm{SCE}$, showing selected granular attack.

Figure 17 shows penetration results for the different tempers of AA2024 alloys at -580 $\mathrm{mV}$ SCE. It is surprising that artificial aging did not produce a significant effect on the penetration rate even though it had a large effect on localized corrosion morphology. The T8 and $\mathrm{T} 3+$ tempers had a slightly slower penetration rate than T3, but there is no clear trend. The data also indicate that AA2024-SHT (water quenched) had almost the same penetration rate as the aged samples.

The attack morphology changed with temper. Figure 18 shows some cross sections of T3+ and T8+ samples. The T3+ temper exhibited sharp IGC morphology at $-580 \mathrm{mV} \mathrm{SCE}$, and directional grain boundary attack at OC, both of which, in general, are very similar to those of T3 temper under the same conditions. However, the localized corrosion morphology for T8+ temper is more like selected grain dissolution as in the case of T8 at $-580 \mathrm{mV} \mathrm{SCE}$. The selective grain attack seen on the T8 and T8+ tempers is consistent with the observation of decreased 


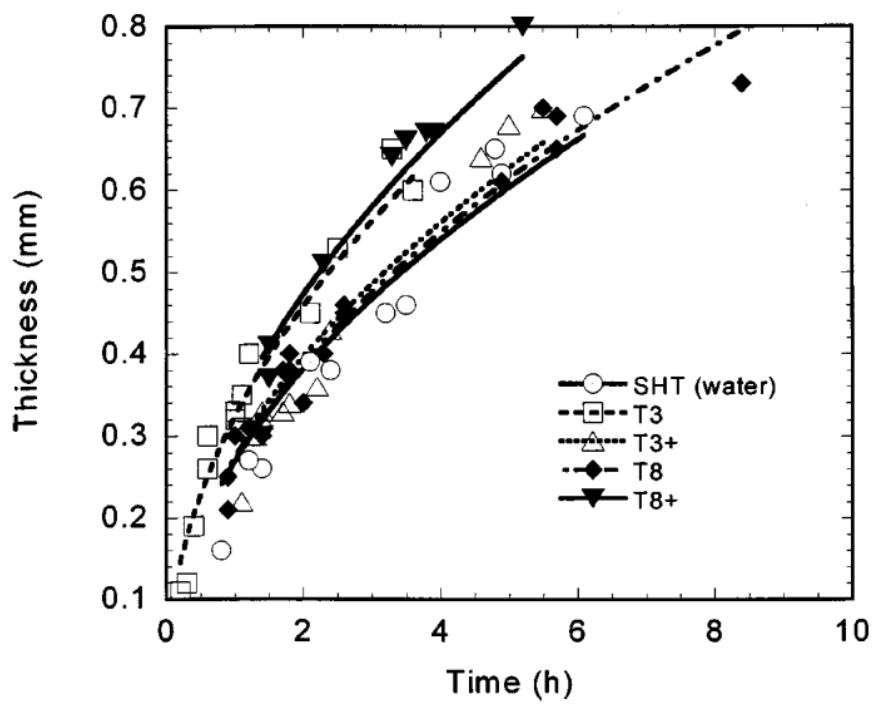

Figure 17. Penetration time for various tempered AA2024 (L) samples at $-580 \mathrm{mV} \mathrm{SCE}$ in $\mathrm{O}_{2}$ bubbled $1.0 \mathrm{M} \mathrm{NaCl}$.

susceptibility to IGC with artificial aging. ${ }^{14}$ The change in the form of attack can be explained by a decrease in $\mathrm{Cu}$ content of the matrix phase with aging, which makes the grain more susceptible to breakdown than the grain boundary or SDZ. However, it is interesting that the attack stays within single grains and does not spread to adjoining grains to become isotropic. It is possible that the less susceptible grain boundary is protected by $\mathrm{Cu}$ deposition in the same fashion as was suggested above for the grain face during sharp IGC of T3 temper. This also explains the lack of potential dependence because the $\mathrm{Cu}$-rich walls would similarly act as local cathodic sites.

Effect of nitrate or sulfate addition.-The effect of nitrate or sulfate addition to the chloride solution on the localized corrosion kinetics was also studied by the foil penetration. Figure 19 shows penetration results for $\mathrm{L}$ sections of AA2024-T3 in $1 \mathrm{M} \mathrm{NaCl}$ solutions containing $0.2 \mathrm{M}$ nitrate or $0.5 \mathrm{M}$ sulfate. A small amount of nitrate or sulfate was added into the chloride solution during the growth stage to exclude a possible inhibition effect on initiation of localized corrosion. The current decreased suddenly upon addition of nitrate to chloride solution during the experiments. However, localized corrosion kinetics were found to be unchanged in the nitrate-containing solution at $-520 \mathrm{mV} \mathrm{SCE}$. Note that the penetration curve forAA2024-T3 in $1.0 \mathrm{MNaCl}$ at $-520 \mathrm{mV} \mathrm{SCE}$ is essentially identical to that at $-580 \mathrm{mV} \mathrm{SCE}$. The IG attack density (number of grain boundaries attacked per unit cross section area) decreased in the nitrate containing solution. One explanation is that the nitrate raised the breakdown potential for IGC, which made it more difficult for IGC to initiate and grow. The penetration rate in $1 \mathrm{MNaCl}+$ $0.2 \mathrm{MNaNO}_{3}$ was slower at $-580 \mathrm{mV}$ compared to that in $1 \mathrm{M} \mathrm{NaCl}$ at $-580 \mathrm{mV} \mathrm{SCE}$ although it was still IGC attack in nature. The reason may be due to the fact that the OCP was raised to about $-580 \mathrm{mV}$ SCE after addition of $0.2 \mathrm{M}$ nitrate in $1 \mathrm{M} \mathrm{NaCl}$. The data at $-580 \mathrm{mV} \mathrm{SCE}$ are very scattered in the nitrate containing solution, similar to those at $\mathrm{OC}$ in the pure chloride solution. 


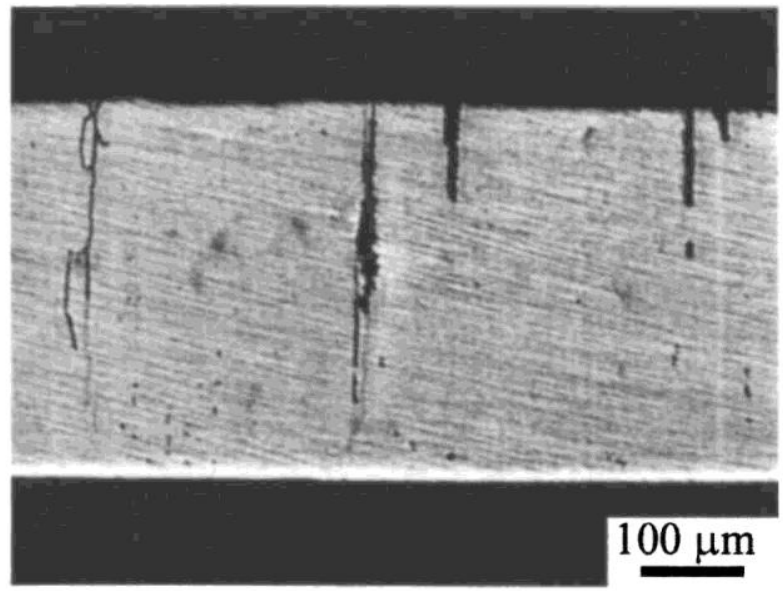

(a)

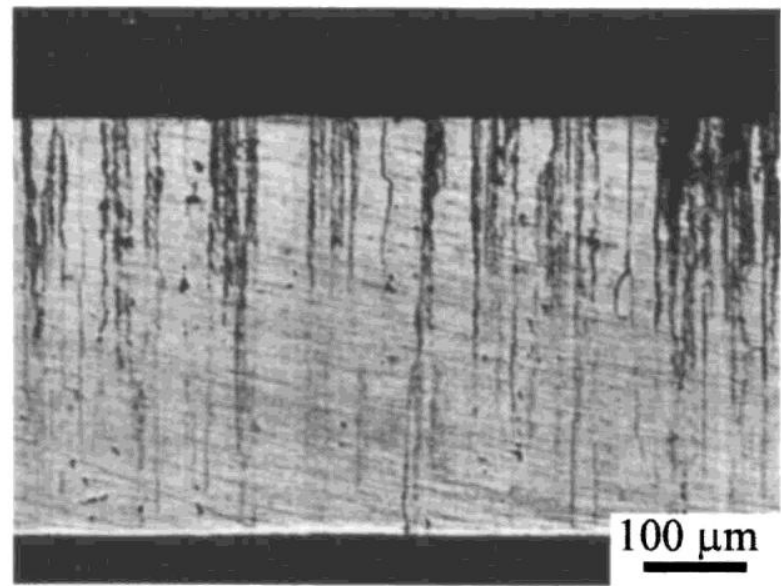

(b)

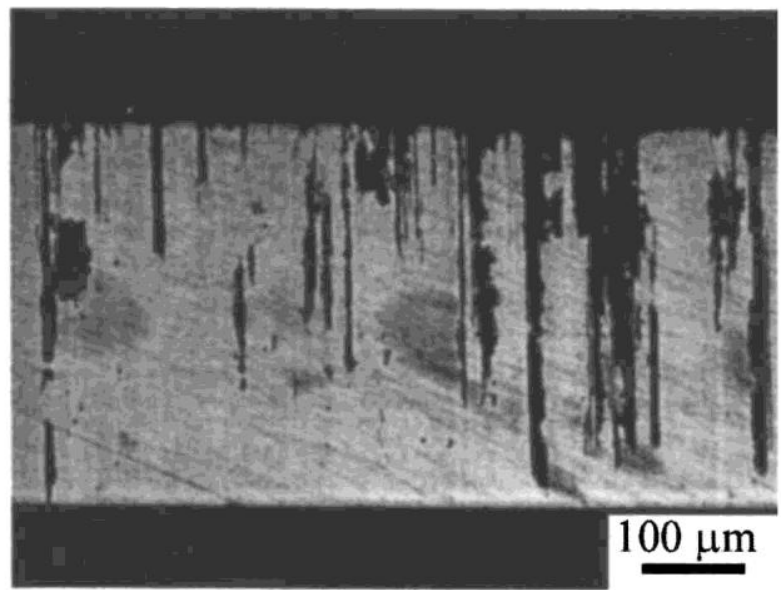

(c)

Figure 18. As polished metallographic cross sections of L samples of AA2024-T3+ and AA2024-T8 + . (a) T3+ temper penetrated at OCP (ca. $-665 \mathrm{mV} \mathrm{SCE})$ for $72 \mathrm{~h}$, (b) T3+ penetrated at $-580 \mathrm{mV} \mathrm{SCE}$ for $2.2 \mathrm{~h}$, and (c) T8+ penetrated at $-580 \mathrm{mV} \mathrm{SCE}$ for $1.8 \mathrm{~h}$. 


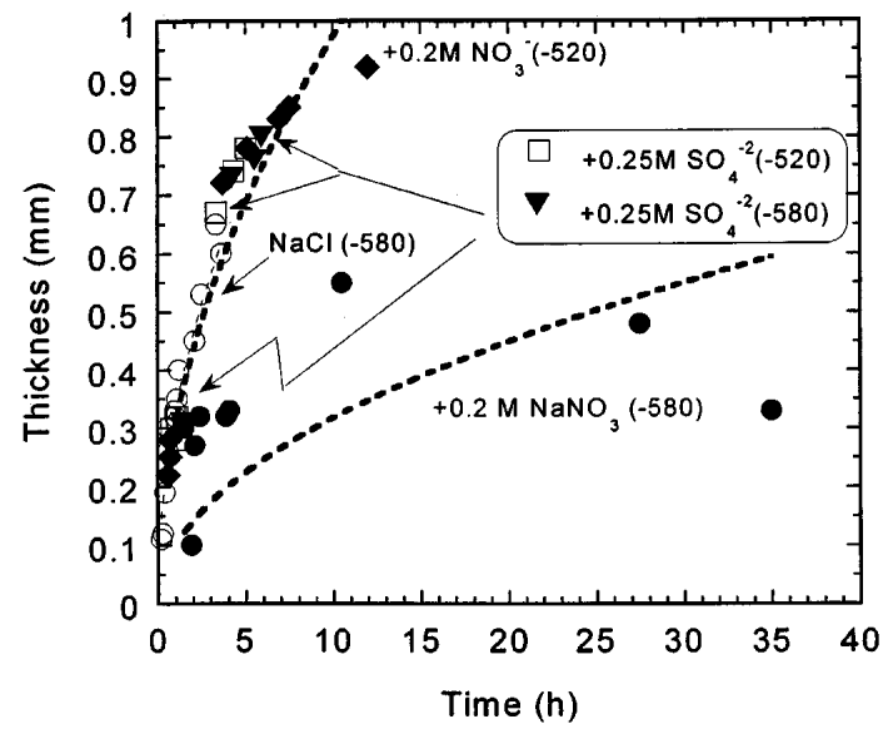

Figure 19. Penetration behavior for $\mathrm{L}$ samples of $1.9 \mathrm{~cm}$ AA2024-T3 in nitrate- and sulfate-containing $1 \mathrm{M} \mathrm{NaCl}$ solutions.

It has been reported that addition of sulfate increases the localized corrosion kinetics by increasing the conductivity of the solution. ${ }^{5,15,16,24}$ However, our penetration experiments show that the addition of sulfate up to $0.25 \mathrm{M}$ concentration did not change localized corrosion kinetics at potentials of -520 and $-580 \mathrm{mV}$ SCE (Fig. 19). The localized corrosion was still IG attack in nature in sulfate-containing chloride solutions. But IG attack density (number of grain boundaries attacked per unit cross section area) decreased in sulfate-containing solution as well.

\section{Conclusion}

The influence of foil orientation, microstructure, artificial aging, and potential on localized corrosion growth and morphology in AA2024 alloys was studied using the foil penetration technique and metallography. Our work has found that

1. The growth kinetics of localized corrosion inAA2024-T3 exhibited a strong anisotropy.

2. The anisotropy of growth kinetics was different for various forms of AA2024-T3 having different microstructures. Both grain size and aspect ratio were important factors in controlling the localized corrosion growth kinetics and morphology.

3. Localized corrosion kinetics and morphology depended on potential. At $-610 \mathrm{mV}$ SCE and higher, the attack in AA2024-T3 was primarily IGC, and the IGC growth was almost independent of potential. The attack was pitlike at very low potentials, where pit growth rate decreased with decreasing potential.

4. The slight increase in IGC growth kinetics with increasing potential from -490 to $+500 \mathrm{mV}$ SCE suggests that only a small amount of anodic current escapes from the active tip of an IGC crack.

5. Artificial aging was found to have a small effect on the localized corrosion growth kinetics even though the morphology changed from sharp IGC to selective grain attack. 
6. The addition of nitrate decreased IGC kinetics at $-580 \mathrm{mV} \mathrm{SCE}$, but had little effect at $-520 \mathrm{mV}$ SCE. Sulfate addition had an insignificant influence on IGC kinetics between -580 and $-520 \mathrm{mV}$ SCE.

\section{Acknowledgments}

This work was supported by the United States Air Force Office of Scientific Research through grant no. F49620-99-1-0103. The authors are grateful to Dr. R. Buchheit for valuable discussions.

The Ohio State University assisted in meeting the publication costs of this article.

\section{References}

1. G. S. Frankel, Corros. Sci., 30, 1203 (1990).

2. K. P. Wong and R. C. Alkire, J. Electrochem. Soc., 137, 3010 (1990).

3. D. W. Buzza and R. C. Alkire, J. Electrochem. Soc., 142, 1104 (1995).

4. H. S. Isaacs and R. C. Newman, Corrosion Chemistry within Pits, Crevices and Cracks,A.Turnbull, Editor, HMSO Books, London (1987).

5. F. Hunkeler and H. Bohni, Corrosion (Houston), 37, 645 (1981).

6. A. Sehgal, G. S. Frankel, B. Zoofan, and S. Rokhlin, J. Electrochem. Soc., 147, 140(2000).

7. W. Zhang and G. S. Frankel, Electrochem. Solid-State Lett., 3, 268 (2000).

8. W. Zhang and G. S. Frankel, Electrochim. Acta, Submitted.

9. M. Posada, L. E. Murr, and R. M. Arrowood, Microstructural Science, 25, 131 (1997).

10. A. L. Campuzano-Contreras, R. M. Arrowood, L. E. Murr, and D. Little, Micro-structural Science, 25, 139 (1997).

11. G. H. Koch, Paper 516, in Corrosion '99, NACE, Houston, TX (1999).

12. A. Rota and H. Bohni, Werkst. Korros., 40, 219 (1989).

13. V. Guillaumin and G. Mankowski, Critical Factors in Localized Corrosion, P. M. Natishan, R. G. Kelly, G. S. Frankel, R. C. Newman, Editors, PV 98-17, p. 203, The Electrochemical Society, Pennington, NJ (1999).

14. M. O. Speidel and M. V. Hyatt, Advances in Corrosion Science \& Technology, M. G. Fontana, R. W. Staehle, Editors, Vol. 2, p. 115, Plenum Press, New York, (1972).

15. F Hunkeler and H. Bohni, Corrosion (Houston), 40, 534 (1984).

16. F Hunkeler and H. Bohni, Corrosion Chemistry within Pits, Crevices and Cracks, A. Turnbull, Editor, p. 27, HMSO Books, London (1987).

17. H. P. Godard, The Corrosion of Light Metals, John Wiley \& Sons, Inc., New York (1967).

18. P. M. Aziz and H. P. Godard, Ind Eng Chem., 44, 1791 (1952).

19. E. Akiyama and G. S. Frankel, J. Electrochem. Soc., 146, 4095 (1999).

20. T. Ramgopal, P. Leblanc, and G. S. Frankel, Unpublished work.

21. R. G. Buchheit, R. P. Grant, P. F Hlava, B. Mckenzie, and G. L. Zender, J. Electrochem. Soc., 144, 2621 (1997).

22. D. O. Sprowls and R. H. Brown, Fundamental Aspects of Stress Corrosion Cracking, R. W. Staehle, A. J. Forty, D. V. Rooyen, Editors, NACE-1, p 466, NACE, Houston, TX (1967).

23. J. R. Galvele and S. M. DeMicheli, Corros. Sci., 10, 795 (1970).

24. A. Sehgal, D. Lu, and G. S. Frankel, J. Electrochem. Soc., 145, 2843 (1998). 